\title{
Середньострокові результати оперативного втручання на брахіоцефальних та вінцевих артеріях у пацієнтів з мультифокальним атеросклерозом
}

\author{
Белейович В. В., Габрієлян А. В., Ратушнюк А. В., Береговой О. В., Кудлай І. В., \\ Романова С. В.
}

\author{
ДУ «Національний інститут хірургії та трансплантології імені О. О. Шалімова» НАМН» (Київ)
}

\begin{abstract}
Атеросклероз - системний дегенеративний процес, який уражає аорту і магістральні судини мозку, серця та інших органів. Аналіз результатів хірургічного лікування пацієнтів з оклюзійно-стенотичним ураженням двох судинних басейнів, серця та головного мозку в середньострокові терміни спостереження в літературі представлений недостатньо.
\end{abstract}

Мета роботи - провести порівняльний аналіз середньострокових результатів хірургічного лікування пацієнтів із поєднаним атеросклеротичним ураженням вінцевих та брахіоцефальних артерій.

Матеріали та методи. Проведено аналіз середньострокових результатів хірургічного лікування 62 хворих із поєднаним атеросклеротичним оклюзійно-стенотичним ураженням сонних та коронарних артерій. Протокол обстеження включав загальноклінічні та спеціальні методи: ЕКГ, ехокардіографію, коронаровентрикулографію, ультразвукове дуплексне сканування сонних артерій, перфузійну комп'ютерну томографію головного мозку.

Результати та їх обговорення. Результат операції та якість життя пацієнтів першої та другої групи дослідження у строки до 6 міс. з кардіологічної точки зору розцінено як добрі у $53(94,6 \%)$ і як задовільні - у 3 (5,4\%) випадках. Ознак ішемії міокарда та повторних інфарктів не спостерігалося. За неврологічним статусом результати розцінено як добрі у 49 (87,5\%) випадках, як задовільні - у 6 (10,7\%), незадовільні - в 1 (1,8\%) причиною став інсульт головного мозку. Статистично значущих відмінностей у результатах оперативного лікування в групах одномоментного та етапного лікування встановлено не було. Негативна динаміка клінічного стану з перебігом часу була зумовлена головним чином прогресуванням основного захворювання.

Висновки. Аналіз результатів симультанного та етапного хірургічного втручання у пацієнтів з оклюзійностенотичним ураженням двох судинних басейнів засвідчив, що розроблена нами тактика вибору методу хірургічної корекції поєднаних уражень вінцевих та брахіоцефальних артерій дозволяє отримати добрі результати в середньострокові терміни спостереження. Стенокардії та повторних інфарктів через 6 міс. після оперативного втручання зареєстровано не було. Тільки в одного пацієнта другої групи, якому виконано етапне оперативне втручання на вінцевих та брахіоцефальних артеріях, відмічалося гостре нефатальне порушення мозкового кровообігу. Таким чином, вибір оптимального підходу до тактики оперативного втручання дозволяє безпечно виконати відновлення кровотоку у пацієнтів із поєднаним ураженням сонних та вінцевих артерій.

Ключові слова: ішемічна хвороба серия, аортокоронарне шунтування, еверсійна каротидна ендартеректомія, атеросклероз, одномоментні операції, етапні операції.

Атеросклероз - системний дегенеративний процес, який уражає аорту і магістральні судини мозку, серця та інших органів. Структурні зміни у стінці артерій еволюціонують від жирових плям і смуг до фіброатероматозних, геморагічних і тромботичних бляшок, які спричиняють клінічно гострі і хронічні ішемічні синдроми: ішемічну хворобу серця (IXC) / гострий коронарний синдром (ГКС); транзиторну ішемічну атаку (ТIA) / гостре порушення мозкового кровообігу (ГПМК) [1, 2, 5]. Серце і головний мозок - взаємопов'язані органимішені судинної патології, клінічні варіанти якої (IXC, ГПМК) лідирують у смертності населення розвинутих країн і є основними інвалідизуючими захворювання- ми, що завдають значних економічних збитків [4, 8].

Покращення діагностики атеросклерозу змінило стандартні уявлення про цю патологію і привело до того, що в клінічній практиці все рідше зустрічаються локальні прояви атеросклеротичного процесу у вигляді добре відомих і звичних синдромів. 3'явилось поняття мультифокального атеросклерозу, що об'єднує особливу категорію пацієнтів із гемодинамічно значущими ушкодженнями артерій у декількох судинних басейнах $[3,6]$. Реконструктивно-відновні операції на сонних артеріях без урахування патології коронарних артерій або відновлення адекватної васкуляризації міокарда без втручання на сонних артеріях можуть приводити 
до незадовільних результатів - ризику периопераційних ускладнень [3, 8].

Аналіз досвіду хірургічного лікування хворих із мультифокальним атеросклерозом свідчить про необхідність строго індивідуального підходу при виборі хірургічної тактики корекції атеросклеротичних ушкоджень, перш за все при виборі об’єму операції, способів інтраопераційного захисту від ішемічних ушкоджень, етапності лікування, зони первинної реваскуляризації $[1,9]$. Проте аналіз результатів хірургічного лікування цієї категорії пацієнтів в середньострокові та віддалені терміни спостереження в літературі представлений недостатньо.

Мета роботи - провести порівняльний аналіз середньострокових результатів хірургічного лікування пацієнтів із поєднаним атеросклеротичним ураженням вінцевих та брахіоцефальних артерій.

Матеріали та методи. Робота грунтується на аналізі результатів хірургічного лікування 62 хворих із поєднаним атеросклеротичним оклюзійно-стенотичним ураженням сонних та коронарних артерій у відділах трансплантації та хірургії серця та хірургії магістральних судин НІХТ імені О. О. Шалімова за період 20122017 рр. Залежно від використаної хірургічної тактики хворі були розподілені на дві групи. До першої ввійшли хворі, яким виконано одномоментні оперативні втручання (35 спостережень) на двох судинних басейнах. Другу групу становили пацієнти, яким виконано етапні операції на сонних та вінцевих артеріях на працюючому серці (27 спостережень). В усіх пацієнтів відмічали поєднані гемодинамічно значущі атеросклеротичні ураження коронарного та каротидного басейнів, що і стало критерієм включення в дослідження. Загальна характеристика груп спостереження наведена в табл. 1 .

Протокол обстеження в доопераційному періоді включав загальноклінічні та спеціальні методи обстеження серцево-судинної системи: ЕКГ, ехокардіографію, коронаровентрикулографію, ультразвукове дуплексне сканування сонних артерій, МСКТ головного мозку.

При аналізі похідного стану пацієнтів (табл. 1) між групами не було суттєвих розбіжностей за показником скоротливості лівого шлуночка серця. ФВ у першій та другій групі збереглась на рівні відповідно $(42,5 \pm 7,9)$ та $(47,3 \pm 5,6) \%$. Незважаючи на однорідність похідного стану у групах спостереження та збереження скоротливої здатності міокарда на задовільному рівні слід відмітити, що в першій групі хворі, як видно з табл. 1, до оперативного втручання клінічно були більш важкі мали більш виражені ознаки декомпенсації коронарного та церебрального кровообігу.

3-поміж супутньої патології провідне місце посідала гіпертонічна хвороба. Практично всі хворі $(88,7 \%)$ мали різний ступінь іiі проявів. Друге місце за значущістю в клінічному стані займав цукровий діабет. Він

\section{Таблиця 1}

Клінічна характеристика обстежених хворих із поєднаним атеросклеротичним ураженням сонних і коронарних артерій $(n=62)$

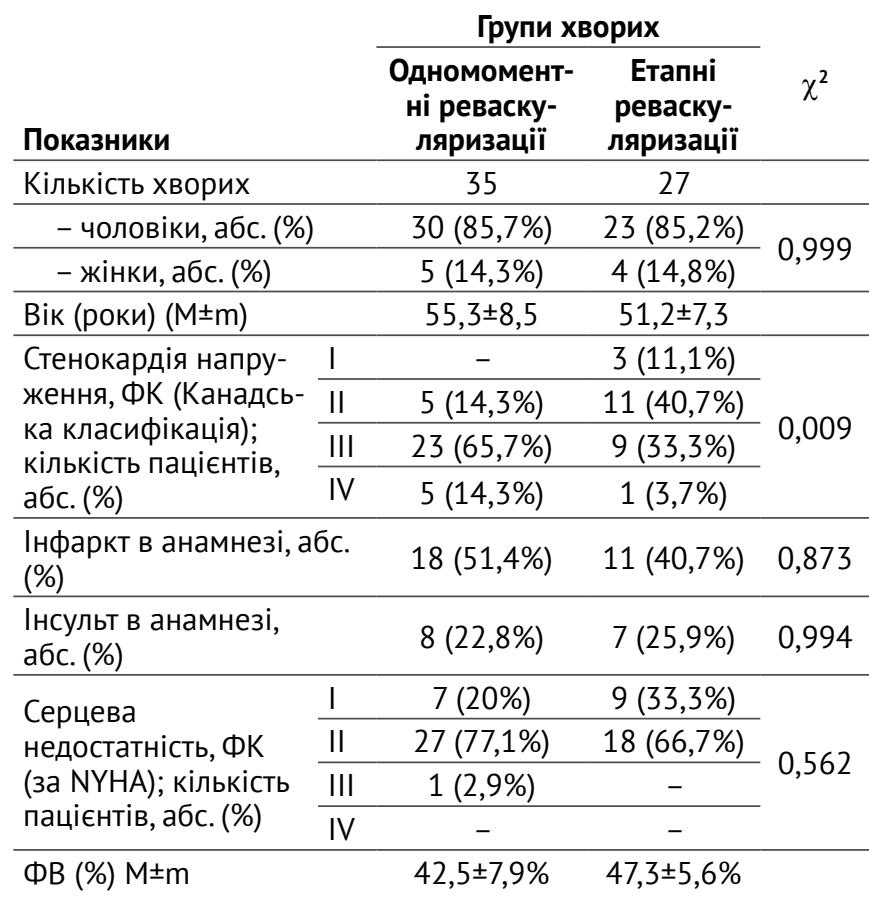

Примітка. Розбіжності між групами статистично не значущі за винятком ФК стенокардії напруження

спостерігався у 50\% пацієнтів. Статистично вірогідних відмінностей між групами за частотою реєстрації супутньої патології не було.

Результати та їх обговорення. Середньострокові результати хірургічного втручання на двох судинних басейнах у пацієнтів із мультифокальним атеросклерозом на основі зіставлення суб'єктивних і об'єктивних клінічних показників через 6 міс. після виписки зі стаціонару були вивчені у 56 із 62 пацієнтів. У першій групі, де виконувались симультанні оперативні втручання на серці та артеріях шиї, було обстежено 31 (88,6\%) пацієнта із 35. У другій групі, де виконувались етапні оперативні втручання (ЕКЕ та АКШ), - відповідно 25 $(92,6 \%)$ із 27 хворих. Шість пацієнтів з різних причин не були обстежені. За хороший і задовільний результат брали очевидне суб'єктивне покращення, нормалізацію або значну позитивну динаміку основних клінічних показників. Результати обстеження пацієнтів через 6 місяців після оперативного лікування узагальнені в табл. 2.

Як видно з табл. 2, пацієнти (n=56, 100\%) відмічали суттєве покращення якості життя та збільшення толерантності до фізичного навантаження: так, при порівнянні похідного стану за ФК NYHA зі станом через 6 


\section{Таблиця 2}

Середньострокові (6 міс.) результати оперативного

лікування хворих з ураженням вінцевих та

брахіоцефальних судин

\begin{tabular}{|c|c|c|c|c|c|c|}
\hline \multirow{2}{*}{\multicolumn{2}{|c|}{ Показники }} & \multicolumn{2}{|c|}{$\begin{array}{c}\text { Симультанні } \\
(\mathrm{n}=31)\end{array}$} & \multicolumn{2}{|c|}{$\begin{array}{l}\text { Етапні } \\
(n=25)\end{array}$} & \multirow[t]{2}{*}{$\chi^{2}$} \\
\hline & & абс. & $\%$ & абс. & $\%$ & \\
\hline \multicolumn{2}{|c|}{$\begin{array}{l}\text { Хороші результати } \\
\text { лікування }\end{array}$} & 28 & 90,3 & 18 & 72,0 & \multirow{3}{*}{0,312} \\
\hline \multicolumn{2}{|c|}{ Задовільні результати } & 3 & 9,7 & 6 & 24,0 & \\
\hline \multicolumn{2}{|c|}{ Незадовільні результати } & - & - & 1 & 4,0 & \\
\hline \multirow{4}{*}{$\begin{array}{l}\text { ФК серцевої } \\
\text { недостатності } \\
\text { за класифіка- } \\
\text { цією NYHA }\end{array}$} & 1 & 24 & 77,4 & 21 & 84,0 & \multirow{4}{*}{0,944} \\
\hline & II & 7 & 22,6 & 4 & 16,0 & \\
\hline & III & - & - & - & - & \\
\hline & IV & - & - & - & - & \\
\hline \multirow{5}{*}{$\begin{array}{l}\text { ФК стенокардії } \\
\text { напруження за } \\
\text { Канадською } \\
\text { класифікацією }\end{array}$} & Відсутні & 19 & 61,3 & 16 & 64,0 & \multirow{5}{*}{0,998} \\
\hline & I ФK & 12 & 38,7 & 9 & 36,0 & \\
\hline & II ФК & - & - & - & - & \\
\hline & III ФK & - & - & - & - & \\
\hline & IV ФК & - & - & - & - & \\
\hline \multirow{4}{*}{$\begin{array}{l}\text { ХНМК за } \\
\text { класифікацією } \\
\text { А.В. Покровсь- } \\
\text { кого }\end{array}$} & 1 & 16 & 51,6 & 11 & 44 & \multirow{4}{*}{0,439} \\
\hline & II & 13 & 41,9 & 9 & 36 & \\
\hline & III & 2 & 6,4 & 4 & 16 & \\
\hline & IV & - & - & 1 & 4 & \\
\hline
\end{tabular}

міс. встановлено, що практично всі пацієнти двох груп дослідження стосовно переносності фізичних навантажень перебували у I та II ФК. Жодного випадку прогресування стадії СН за Нью-Йоркською Асоціацією Кардіологів зареєстровано не було.

У переважної кількості пацієнтів $(\mathrm{n}=35,62,5 \%)$ у середньострокові терміни спостереження після хірургічної корекції були відсутні скарги на прояви стенокардіï. За даний проміжок часу жодного випадку коронарної події зареєстровано не було, оскільки клінічно пацієнти почували себе добре, без ознак ішемії міокарда та повторних інфарктів міокарда. У 3 (5,5\%) пацієнтів двох груп дослідження спостерігалась деяка негативна динаміка щодо роботи серця порівняно з безпосередніми результатами лікування, що може бути зумовлено прогресуванням основного захворювання. Ми відкоригували медикаментозне лікування, що в подальшому привело до покращення самопочуття хворих.

При аналізі скарг неврологічного статусу в пацієнтів після 6 міс. 3 моменту оперативного втручання на двох судинних басейнах встановлено, що переважна більшість хворих ( $\mathrm{n}=49,87,5 \%)$ двох груп дослідження перебували у I-II стадії ХНМК, що свідчило про відсутність нових післяопераційних вогнищ ішемії головного мозку. В переважній більшості випадків зареєстровані скарги на системне головокружіння, розлади спілкування, періодичну слабкість у нижніх і верхніх кінцівках. Але пацієнти відмічали, що їх частота та прояви менші порівняно з доопераційним станом. У $6(10,7 \%)$ хворих двох груп відмічалися скарги на значне погіршення пам'яті, дискуляторну енцефалопатію та зниження інтелекту. В 1 (4\%) пацієнта другої групи, якому виконано етапне оперативне втручання на вінцевих та брахіоцефальних артеріях, результат операції визнано незадовільним. Причиною такого стану послугував повторний ішемічний інсульт, який призвів до інвалідності. На нашу думку, мозкова пригода могла статися внаслідок емболізації екстра- та інтракраніальних судин.

Таким чином, результат операції та якість життя пацієнтів першої та другої групи дослідження у строки до 6 міс. $з$ кардіологічної точки зору розцінено як добрі у $53(94,6 \%)$ і як задовільні - у $3(5,4 \%)$ випадках. Ознак ішемії міокарда та повторних інфарктів не спостерігалося. За неврологічним статусом результати розцінено як добрі у $49(87,5 \%)$ випадках, як задовільні - у $6(10,7 \%)$, незадовільні - в $1(1,8 \%)-$ причиною став інсульт головного мозку. Статистично значущих відмінностей результатів оперативного лікування в групах одномоментного та етапного лікування встановлено не було. Негативна динаміка клінічного стану з перебігом часу була зумовлена головним чином прогресуванням основного захворювання.

Висновки. Аналіз результатів симультанного та етапного хірургічного втручання у пацієнтів з оклюзійно-стенотичним ураженням двох судинних басейнів показав, шо розроблена нами тактика вибору методу хірургічної корекції поєднаних уражень вінцевих та брахіоцефальних артерій дозволяє отримати добрі результати в середньострокові терміни спостереження. Стенокардії та повторних інфарктів через 6 міс. після оперативного втручання зареєстровано не було. Тільки в одного пацієнта другої групи, якому виконано етапне оперативне втручання на вінцевих та брахіоцефальних артеріях, відмічалося гостре нефатальне порушення мозкового кровообігу. Таким чином, вибір оптимального підходу до тактики оперативного втручання дозволяє безпечно виконати відновлення кровотоку у пацієнтів із поєднаним ураженням сонних та вінцевих артерій.

\section{Література}

1. Диагностический подход и результаты хирургического лечения у больных с сочетанной патологией брахиоцефальных и коронарных артерий / Бокерия Л. А., Асланиди И. П., Дарвиш Н. А. и др. // Бюл. НЦССХ им. А. Н. Бакулева РАМН. Сердечнососудистые заболевания. - 2012. - № 3 (5). - С. 51-9.

2. Характеристика атеросклеротических изменений сонных артерий по данным мультиспиральной компьютерной томографии при метаболическом синдроме / Праскурничий Е. А., Александрова И. И., 
Костычева Т. В. и др. // Клин. медицина. - 2017. № 95 (1). - C. 51-6.

3. ACCF/SCAI/SVMB/SIR/ASITN 2007 clinical expert consensus document on carotid stenting: a report of the American College of Cardiology Foundation Task Force on Clinical Expert Consensus Documents (ACCF/ SCAI/SVMB/SIR/ASITN Clinical Expert Consensus Document / Bates E. R., Babb J. D., Casey D. E. Jr. et al. // J Am Coll Cardiol. - 2007 Jan. - Vol. 49 (1). - P. 126-70.

4. Early results after synchronous carotid stent placement and coronary artery bypass graft in patients with asymptomatic carotid stenosis / Barrera J. G., Rojas K. E., Balestrini C. et al. // J Vasc Surg. - 2013 Feb. - Vol. 57 (2 Suppl). $58 \mathrm{~S}-63 \mathrm{~S}$.

5. Boren J., Williams K. J. The central role of arterial retention of cholesterol-rich apolipoprotein-B-containing lipoproteins in the pathogenesis of atherosclerosis: a triumph of simplicity // Curr Opin Lipidol. - 2016 Oct. Vol. 27 (5). - P. 473-83.

6. Cerebrovascular reserve and stroke risk in patients with carotid stenosis or occlusion. A systematic review and meta-analysis / Gupta A., Chazen J. L., Hartman M. et al. // Stroke. - 2012. - Vol. 43. - P. 2884-91.

7. Noiphithak R., Liengudom A. Recent update on carotid endarterectomy versus carotid artery stenting // Cerebrovasc Dis. - 2017. - Vol. 43 (1/2) . - P. 68-75.

8. Rapid progression of coronary atherosclerosis: a review / Shah P., Bajaj S., Virk H. et al. // Thrombosis. - Vol. 2015 (2015). - Article ID 634983. - 6 p.

9. Perioperative strokes following combined coronary artery bypass grafting and carotid endarterectomy: A nationwide perspective / Udesh R., Cheng H., Mehta A. et al. //. Neurol India. - 2018 Jan-Feb. - Vol. 66 (1). - P. 57-64.

\title{
Medium-term results of surgical intervention on brachiocephalic and coronary arteries in patients with multifocal atherosclerosis
}

\author{
Beleyovych V., Gabrielyan A., Ratushnyuk A., Beregovoy O., Kudlai I., Romanova S. \\ National Institute of Surgery and Transplantatology by O. Shalimov NAMS of Ukraine (Kyiv)
}

Atherosclerosis is a systemic degenerative process that affects the aorta and the great vessels of the brain, heart and other organs. The analysis of the results of surgical treatment of patients with occlusive-stenotic lesion of two vascular pools, heart and brain in the medium-term follow-up period is insufficiently highlighted in the literature.

The purpose of the work. To carry out a comparative analysis of the medium-term results of surgical treatment of patients with combined atherosclerotic lesions of the coronary and brachiocephalic arteries.

Materials and methods. The analysis of medium-term results of surgical treatment of 62 patients with combined atherosclerotic occlusive-stenotic lesion of carotid and coronary arteries was carried out. The research protocol included general clinical and special methods: ECG, echocardiography, coronaro-ventriculography, duplex ultrasound scanning of the carotid arteries, perfusion computed tomography of the brain.

Results and discussion. The result of surgical intervention and patient QoL of the first and second study groups in terms of up to 6 months were evaluated from the cardiological point of view, as good in 53 cases (94.6\%), and as satisfactory in 3 cases $(5.4 \%)$. There were no evidence of myocardial ischemia and recurrent myocardial infarction. Neurological status was assessed as good in 49 cases $(87.5 \%)$, as satisfactory - in 6 cases $(10.7 \%)$ and unsatisfactory - in 1 case $(1.8 \%)$, where the cause was cerebral stroke. There were no statistically significant differences in the results of surgical treatment in the groups of single-stage intervention and stepped therapy. The negative dynamics of the clinical state over time was due mainly to the progression of the underlying disease.

Conclusions. The analysis of the results of single-stage intervention and stepped therapy in patients with occlusivestenotic lesion of two vascular pools established that the tactic of choosing the method of surgical correction of combined lesions of the coronary and brachiocephalic arteries developed by us allows us to obtain good results in the medium-term follow-up period. Angina pectoris and recurrent myocardial infarction at 6 months after surgery were not recorded. Only in 1 patient of the second group, that received stepped therapy on the coronary and brachiocephalic arteries, had acute nonfatal cerebral circulatory disorders. Thus, the choice of the optimal approach to the tactics of the operative intervention allows to safely performing the restoration of blood flow in patients with combined lesions of the carotid and coronary arteries.

Key words: ischemic heart disease, coronary artery bypass grafting, eversion carotid endarterectomy, atherosclerosis, singlestage intervention, stepped therapy.

\section{Среднесрочные результаты оперативного вмешательства на брахиоцефальных и коронарных артериях у пациентов с мультифокальным атеросклерозом}

\author{
Белеевич В.В., Габриелян А. В., Ратушнюк А. В., Береговой О. В., Кудлай И. В., Романова С. В. \\ ГУ «Национальный институт хирургии и трансплантологии имени А. А. Шалимова НАМН» (Киев)
}

Атеросклероз - системный дегенеративный процесс, который поражает аорту и магистральные сосуды мозга, сердца и других органов. Анализ результатов хирургического лечения пациентов с окклюзионно-стенотическим 
поражением двух сосудистых бассейнов, сердца и головного мозга в среднесрочный период наблюдения в литературе представлен недостаточно.

Цель работы - провести сравнительный анализ среднесрочных результатов хирургического лечения пациентов с совмещенным атеросклеротическим поражением коронарных и брахиоцефальных артерий.

Материалы и методы. Проведен анализ среднесрочных результатов хирургического лечения 62 больных с сочетанным атеросклеротическим окклюзионно-стенотическим поражением сонных и коронарных артерий. Протокол обследования включал общеклинические и специальные методы: ЭКГ, эхокардиографию, коронаровентрикулографию, ультразвуковое дуплексное сканирование сонных артерий, перфузионную компьютерную томографию головного мозга.

Результаты и их обсуждение. Результат операции и качество жизни пациентов первой и второй группы исследования в сроки до 6 мес. оценены с кардиологической точки зрения как хорошие в 53 (94,6\%) и как удовлетворительные в $3(5,4 \%)$ случаях. Признаков ишемии миокарда и повторных инфарктов не наблюдалось. По неврологическому статусу результаты оценены как хорошие в $49(87,5 \%)$ случаях, как удовлетворительные - в 6 $(10,7 \%)$ и неудовлетворительные - в $1(1,8 \%)$ - причиной стал инсульт головного мозга. Статистически значимых различий результатов оперативного лечения в группах одномоментного и этапного лечения установлено не было. Отрицательная динамика клинического состояния с течением времени была обусловлена главным образом прогрессированием основного заболевания.

Выводы. Анализ результатов симультанного и этапного хирургического вмешательства у пациентов с окклюзионно-стенотическим поражением двух сосудистых бассейнов показал, что разработанная нами тактика выбора метода хирургической коррекции сочетанных поражений коронарных и брахиоцефальных артерий позволяет получить хорошие результаты в среднесрочный период наблюдения. Стенокардии и повторных инфарктов через 6 мес. после оперативного вмешательства зарегистрировано не было. Только у одного пациента второй группы, которому выполнено этапное оперативное вмешательство на коронарных и брахиоцефальных артериях, отмечалось острое нефатальное нарушение мозгового кровообращения. Таким образом, выбор оптимального подхода к тактике оперативного вмешательства позволяет безопасно выполнить восстановление кровотока у пациентов с сочетанным поражением сонных и коронарных артерий.

Ключевые слова: ишемическая болезнь сердиа, аортокоронарное иунтирование, эверсионная каротидная эндартерэктомия, атеросклероз, одномоментные операции, этапные операции. 